\title{
The Proof of Economic Welfare Is in the Eating of Nutritious Diets by the Resource-Poor: A Political Economy Analysis of the International Evidence of Dietary Consumption in Rural Africa
}

\author{
Gamel Abdul-Nasser Salifu ${ }^{1}$ \\ ${ }^{1}$ Department of Economics, School of Liberal Arts and Social Sciences, Ghana Institute of Management and Public \\ Administration, Achimota, Accra, Ghana \\ Correspondence: Alhaji Gamel Abdul-Nasser Salifu, Department of Economics, School of Liberal Arts and Social \\ Sciences, Ghana Institute of Management and Public Administration, Achimota, Accra, Ghana.
}

Received: December 10, 2020

Accepted: January 20, 2021

Online Published: January 27, 2021

doi:10.5430/ijba.v12n1p57

URL: https://doi.org/10.5430/ijba.v12n1p57

\begin{abstract}
This paper provides a summary of the international literature published in the thematic area of household dietary diversity with emphasis on the importance of sustainable approaches to global hunger and malnutrition. The paper highlights the correlation between inadequate household dietary diversity, child mortality and death. It also draws attention to the subtle combinations of social, economic and political interactions in enhancing nutritional welfare. The paper further raises a major argument that contemporary explorations of dietary diversity have failed to sustain the important tension and dialectical debate between diverse empirical realities and wider theorization of the concrete linkage of economic welfare to dietary diversity. The paper sets the tone for wider conceptualization of the phenomenon by clearly outlining the role of multiple relations of low incomes, inadequate maternal-child health care as well as poor environmental sanitation as leading predicators of under-nutrition in rural Africa. This theorization makes the case that, studying the relations and conjunctions of economic welfare via the agency of dietary consumption, is critical for emergent processes of change as the given-evidence of under-nutrition does not allow economists to draw solid conclusions on status of dietary diversity in rural Africa without a dynamic understanding and explicit recognition of the wider abstractions of political economy undercurrents in economic welfare and nutritional well-being literature. That said, the paper re-affirms the subtle evidence that under-nutrition and reduced body-mass of adults, often cited in the development literature as proxy-indicators of poor dietary diversity, needs to be re-evaluated as reduced body-mass in adults could be an indication of other incidences of environmental-stresses rather than of food-energy stress. In this vein, the review sustains a new argument that, resource-poor households modify attitude to food consumption in order to self-protect against income losses in household production systems. This position has implications for economic welfare and nutritional diversity research as food may not always come first for the resource-poor. It also opens new avenues for economic research by projecting the hypothesis that consumption of nutritious diets cannot be seen as a unique object to be sought by resource-poor to the exclusion of all other priorities including raising income frontiers through savings for wealth accumulation. The pre-eminence of food security over income diversification activities of rural households as a broader strategy to reduce malnutrition and poverty in the developing world could be re-examined to give livelihood activities a central role in household dietary diversity research.
\end{abstract}

Keywords: economic welfare, food insecurity, malnutrition, household dietary diversity, food-energy stress, hunger, resouce-poor, resilience, sustainable development

\section{Introduction}

The political economy analysis of household dietary diversity is taking centre stage in economic literature as global trends in food security continue to decline from the devastating impact of the Covid-19 pandemic which recently struck world food markets (Salifu, 2020; Devereux, Béné, \& Hoddinott, 2020; Anaman, 2018). Global statistics indicate that more than 1 billion people in the developing world have been displaced by the food crises and shortages (FAO, 2019). It is estimated that 155 million people in Sub-Saharan Africa are reportedly food insecure and malnourished (World Bank, 2020, FAO, 2018). In otherwords, resource- poor households were hungry throughout the day or went to bed without eating the required variety of food groups necessary to maintain a healthy life 
(Hopkins 1986; Dzanku, 2019). Dietary diversity as a vital component of adequate nutrition consumption measures calories of energy intake by toddlers, teenagers, pregnant and lactating mothers within the household (Seidu, Ahinkorah, \& Agbablo, 2020; Ecker, 2018, Fentahun, Seid, \& Biruk, 2018). Resource-poor households are said to be nutritionally- insecure if the meals they consume woefully lack the dietary quality and micro-nutrient composition to ensure a productive life (Laborde, Martin, \& Vors, 2020; Bickel, Andrews \& Klein, 1996).

The renewed global call for dietary diversity research in this decade is fed by three major rivers. First, is the growing interest of international development community to ascertain the status of malnutrition and malnourishment in the developing world; second, is the paucity of panel data on household dietary diversity trajectories essential for setting new development benchmarks for malnutrition policy interventions in rural parts of Africa. Third, the plethora of empirical studies have yet to fully account for the widening chasm between achievement of food security goals and under-achievement of dietary diversity targets in experimented regions of the developing world (Bickel, Nord, Price, Hamilton \& Cook, 2000, Bene, 2020). Although experimental evidence strikes a delicate balance between food security and dietary diversity, it fails to fully account for the growing effects of food poverty and deprivation despite several international policy interventions to address the problem in affected regions.

This has prompted new global discussions on how to feed the future through improvement of the mesurements of the qualitative perceptions of households regarding dietary diversity outcomes (Moniruzzaman, 2020; Reardon, Delagado \&Matlon, 1992). It must be stated right from the onset that, while food security literature clearly distinguishes the four underlying dimensions of food security; availability, access, utilization and stability there is growing controversy regarding the standard approaches to the proper estimation of dietary diversity among rural households. One major emerging concern in the literature is the failure of food security paradigms to inculcate new components of dietary quality, food safety and cultural preference in food security monitoring and screening efforts around the world.

That notwithstanding current food security studies has adequately quantified the function of dietary diversity as a major outcome of household welfare in Sub-Saharan Africa where two-thirds of rural women and children are reportedly malnourished. However, the measurement and improvement of the global understanding of the nexus between food security and household dietary diversity still leaves much to be desired in many parts of rural Africa. Hence, household dietary diversity research has become imperative in global poverty reduction strategies for sustainable development (Narayanan, 2020; Dithmer \& Abdulai, 2017; Deaton \& Lipka, 2015). This is crucial as food insecurity perpetuated by low productivity in stable food production, variability in food supply and price shock effects assume alarming dimensions in the developing world (Salifu \& Anaman, 2019a; Ashley \& Carney, 1999; Bebbington, 1999). Several countries have consistently recorded low deficits in staple food production and hiking food prices by more than 30 percent within the last 5 years alone. The implication is that resource-poor households whose incomes are below the minimum cost of the food basket are nutritionally insecure and less resilient.

The purpose of this paper is to clarify the concept of dietary diversity as a vital component of economic welfare in rural Africa. Without seeking to underestimate the relevance of other dimensions of food security in poverty reduction analysis, political economy analysis of household dietary consumption patterns remains the missing gap in the global efforts of enhancing the effective implementation and administration of nutrition goals in integrated rural development programmes. Accounting for political economy perspectives in household diversity research is one of the single most important factors explaining the wide variation in household well-being and consumption patterns in recent times. The tendency of development policies to play glancing attention to political economy factors driving inadequate household dietary consumption patterns in rural Africa is perhaps the most important reason for failure of development policies to overturn the devastating impacts of food insecurity and malnutrition.

The structure of this paper is as follows; the core concepts of household dietary diversity have been highlighted, the justification for the introduction of the holistic political economy approaches to dietary diversity analysis has been captured. This is followed by a discussion of the growing risk of under-nutrition and poor dietary diversity in rural Africa. The rest of this paper is devoted to the discussion of the measurement of household dietary diversity and the nutritional strategies adapted by poor households in response to the growing threats of hunger and malnutrition. This is concluded with approaches of rural households to under-nutrition, policy recommendations and suggested areas for further research.

The main objective of this paper is to assemble the various theories and empirical works undertaken in the thematic area of rural household dietary diversity that provide cross-cultural and multidisciplinary approaches to the understanding of nutritional security as a key welfare outcome for resource-poor households of rural Africa. This paper contributes to the international political economy literature by providing a synthesis of research works 
undertaken over the last 70 years and indicating gaps in the literature which may prompt new research works to advance the analysis of household dietary diversity and its linkages to economic welfare as an important policy tool to reduce poverty around the world.

\subsection{Systematic Economic Review Methodology}

The analytical approach adopted for this review favours the fundamental techniques of standard systematic literature review practices in the welfare economics discipline. The techniques followed the systematic process of explicit and transparent literature sampling, selection, analysis and synthesis of economic studies reported in world class journals of economics. The review adopted a four- step process; first, determining research questions to guide the review; second, developing a search protocol (targeted systematic databases) and search terms to explore literature databases; third, screening the results of literature databases based on their relevance to research questions and fourth; conducting analysis and synthesis of the remaining literature.

The main objective of the systematic review methodology was to interogate the relevance of the concept of food security and dietary diversity to rural economic welfare. For this purpose, two research questions were framed. The first question sought to understand how contemporary literature on household dietary diversity intergrated in practice, the essential features of welfare economics in the analytical approaches used. The review interrogated the quality of the studies based on a consideration of a number of factors. An important factor was to identify multidimensional power relations in conceptualizing, describing and assessing the processes and outcomes of household welfare in the developing world. The second question focused on the essential features of household dietary diversity and other vital components of welfare economics which fashioned out an effective and sustainable workable approach to achieving dietary diversity for resource poor in rural Africa.

The study consulted key economic science databases for the review. It concentrated on databases which had a broad range of journals related to household welfare and dietary diversity themes. It focused on the principal topics of relevance to a grounded study of household dietary diversity. The selected databases were interrogated using key words that identified specific authors drawing on their knowledge and practical experience. The analytical review covered a range of peer-reviewed journal articles published over the last 60 years and appeared in the social sciences citations index. The 100 papers carefully conscripted for the review were analysed individually and synthesized into a single paper capturing the important dimensions of household dietary diversity and economic welfare.

\section{Political Economy Analytical Approaches to the Estimation of Household Dietary Diversity Index}

Empirical studies around the world have revealed a range of factors driving household dietary diversity indices in rural Africa. Although the studies employ complex neo-classical equations in modelling household dietary consumption patterns in rural Africa (Abebaw, Admassie, Kassa \& Padoch, 2020; Kodua \& Anaman, 2020; Adelekan \& Omotayo; 2017 \& Campbell, 1990). The empirical approaches have neglected the political economy dimensions of nutritional insecurity which outline the relevance of power structure relations in the estimation of the intensity of household dietary diversity (Allanson, Kasprzyk, \& Barnes, 2017; Cameron \& Worwick, 2003). The political economy analytical perspective is relevant as it provides an intergrated multifunctional approach to the holistic investigation of the complex problem of household dietary diversity (Akirinde, Omotesho \&Ogunla, 2018; Lang \& Barling, 2012).

The political economy approach which employs the simultaneous use of complementary models in the evaluation of dietary diversity is seen as a better approach to nutritional security analysis as the historical use of single-paradigm neo-classical theories have failed to accomplish desirable-end-goals (Amadou, 2019; Anderson 2012; Paarlberg, 2002). One of the major reasons for the failure is the poor conceptualization of the methodologies behind nutritional diversity analysis (Ding \& Abdulai, 2020; Angelsen, et.al, 2014).

Development policies which adequately intergrate all the multi-dimensional facets of rural household resilience to food insecurity and malnutrition are non-existent (Salifu, 2019; Barrette, Bezuneli, Aboud, Upton, Cisse \& Barrette, 2016). The social development policy frameworks have emphasised full-cost recovery measures without the intergrated dimension of the role of institutions in enhancing the capacities, constraints and opportunities of resource-poor households to optimal dietary diversity outcomes. This is required in new times as the policy environment surrounding the effective utilization of resources for attainment of economic welfare goals become important. The exploration of the nexus between economic welfare, dietary diversity and institutions is essential to modeling robust household dietary diversity functions in the developing world (; Baliki, Bruck, \& Stojetz, 2018; Barette \&Reardon, 2000; Bebbington, 1999).

The emphasis of political economy analytic approaches in global economic welfare and malnutrition research is 
extremely relevant because it incorporates the simultaneous use of several complementary lenses to investigate the challenge of meeting economic welfare and food security goals as population dynamics escalate in urban centres (Salifu, 2020). This approach simply argues that the use of single paradigm approaches to solve multi-facted related problem of food insecurity with social, economic and political interactions is certainly inadequate to address the complex problem of under-nutrition in rural Africa especially in low-middle-income countries such as Ghana and Nigeria.

The review of the evidence on household dietary diversity shows that the overarching use of neoclassical Marxist models for investigating the complex issue of rural food insecurity have failed to adequately establish the linkage between economic welfare and nutrition outcomes. Establishing this linkage is crucial in the examination of the relationship between economic welfare, food security and dietary diversity at the household level because food security is not synonymous with dietary diversity. What emerges from the literature is that food security goals have not addressed nutritional dietary objectives of rural households. A deeper multi-sectional framework which clearly identifies and models all the underlying factors driving food poverty and nutritional insecurity is essential in rural development planning and decentralization work. This is why political economy approach to analysis of food and nutritional security has gained widespread acceptance in economic literature.

\section{Measurement of the Indicators of Household Dietary Diversity}

The current strategies for measurement of appropriate indicators of dietary diversity outcomes derive from the original studies of food security concepts which intergrated household diversity with rural development and nutritional planning works of the early 1950s (Forero-Cantor, Ribal, \& Sanjuán, 2020; Brück \& d'Errico, 2019; Bellemare, 2015 and Messer, 1990). These strategies identified the measurement of dietary diversity as vital components of food security analysis (Devereaux, Bene, Hoddinott, 2020; Eide, 1986). Throughout the decades several development studies have clarified the deep linkages between food security processes and nutrition outcomes for rural households (Castro-Arce \& Vanclay, 2020). Hence, rural household dietary diversity research focuses on measuring the dietary quality and micro-nutrient composition of meals consumed by rural people in a recall period.

The Household Dietary Diversity Index (HDDI) is by far the most important construct for assessing nutritional diversity. This tool is cited by literature as a unique and most pratical construct for measurement of rural household nutritional insecurity (Dzanku, \& Sarpong, 2011; Maxwell, 1990; and Balaam, 1986). This scale has been adapted by food security studies to evaluate the dietary quality of meals consumed by poor households and their subceptibility to epidemiological disesases such as malaria, guinea worm, brulli ulcer (Ahmed \& Gasparatos, 2020). Households which record low dietary diversity scores manifest several symptoms of diseases due to crisis in food intake and energy stress (d'Errico, Romano, \& Pertrelli, 2018). Poor dietary diversity manifests in rural adults as loss in body-mass and stunted growth in children (Bene, Headey, Haddad, von Grebmer, 2016).

This is why empirical studies of household dietary diversity have consistently employed anthropometric measures of reduced body- mass, height for age, weight for age and other stagnant growth indicators among pre-schoolers as guiding of factors of nutritional welfare. (Durão,.et al. 2020; Gillespe, van den FAO, 2019; Bold, 2017). The main debate in the literature is to resolve the issue of whether under-nutrition often measured as stagnant growth in children due to low energy intake or reduced body-mass in adults are adequate proxy for indication of poor dietary diversity among resource-poor households (Baliki, Bruck, \& Stojetz, 2018; Barrett, Reardon, \& Webb, 2001 and de Haan, 2000).

\section{Household Dietary Diversity and Rural Welfare}

Empirical studies have shown a positive linkage between adequate household dietary diversity and welfare impacts such as improved health and education of pre-schoolers in rural Africa. Some studies have evaluated the impact of dietary diversity on household welfare using total food expenditures as proxies for measuring the food and nutritional security status of rural households (Bush \& Martiniello, 2017; Bickel, Andrews, \& Klein, 1996). In the context of this paper the debate as to which indicator is proxied by household dietary diversity in rural Africa is revisited. This paper argues that although under-nutrition could be an indication of nutritional insecurity in children, the reduced body mass of adults could be an indication of other incidences of stress independent of food stress.

Understanding all other factors contributing to reduced body-mass of adults is essential for investigating household dietary welfare of resource-poor (Chamberlina \& Jayne, 2020). Establishing this clarity within the context of development literature helps in the efficient design of food security monitoring and signalling outcomes for vulnerable communities of rural Africa where two-thirds of children are reportedly malnourished and pregnant women have gone for months without eating nutritious diets. This situation is depressing as progress in economic 
growth of African countries has not reflected a change in the living standards of resource-contrained poor.

Despite the economic improvements of African countries in the last decades, global hunger index reports high rural infant mortality in several countries. Malnutrition is a serious problem among rural preschoolers of rural Africa which have no school feeding programme components to education. A reanalysis of global trends of rural household malnutrition based on the World nutrition situation ( $\mathrm{ACC} / \mathrm{SCN}, 93)$ confirms the prevalence of high levels of malnutrition among children of rural Africa. In keeping with the international standards used by World Health Organisation, which uses data from the U.S National Centre for Health Statistics (NCHS, 1976), surveys collected on anthropometric and health data of preschoolers under age six indicates that diarrhea, fever, acute respiratory infections and major chronic illnesses requiring surgery are common among children of sub-saharan Africa including Ghana (Harrigan, 2014).

Rural populations of sub-saharan Africa have in recent times reported food and nutritional insecurity with several households going to bed without food due to market failure in agricultural production systems (FAO, 2018). The proportion of adult populations with symptoms of chronic energy deficiency problems have increased in the last few years (Kahsay \& Mulugeta, 2014). However, diagnosing the chronic energy deficiency (CED) in adults has been hampered by lack of precise methods of identifying affected persons (Ravallion \& Chaudhuri, 1997).

Recent approaches of identifying CED in children is to measure body weight in relation to height expressed as body mass index (BMI). Weight in (kilograms) divided by square of height in (metres). Studies show that a BMI of 19.0 is the cut-off rate adequate for good adult health in rural areas. James, Ferro-Luzzi, Waterlow (1988) suggest three cut-offs for rural adults. BMI below 16.0 indicates a third degree CED; 16.0-16.9 indicates a second degree CED, 17.0-18.9 indicates a first-degree CED. Literature shows that overall BMI averages and patterns in major parts of rural Africa are lower among rural households of Africa than in Asia and Latin America (Bolarinwa, Ogundari \& Aromalaran, 2019).

\section{Global Assessment of Household Dietary Diversity}

New global discussions on household dietary diversty are focused on feeding the future and making improvements in the measurement of dietary diversity among resource-poor households. These new concerted are deeply linked to the international development agenda of zero tolerance for hunger and malnutrition by 2030 (Chamberlina \& Jayne, 2020; Pinstrup-Andersen, 2009). The Global Hunger Index (GHI) designed by the International Food Research Insititute (IFPRI) which tracks progress and setbacks of various countries has signicantly improved the assessment and understanding of household dietary diversity in the developing world. It continues to monitor and streamline regional efforts of achieving global food and nutritional security for all people (Headey \& Ecker, 2012).

Empirical studies around the world have identified several causative models of inadequate dietary diversity and malnutrition (Ahmed \& Gasparatos, 2020; Durão, et al. 2020; UNICEF, 1990; Beghin et al., 1988; Pacy \& Payne, 1985 \& Mason et al. 1984). These studies have established a direct correlation between inadequate dietary consumption and death. These studies concede that efforts of solving the poor dietary phenomenon have failed because of the subtle combinations of social, economic and political interactions in nutritional security of households not clearly envisioned by the development literature.

Studies have concluded that dietary diversity inadequacy leading to mortality is precipitated by three major factors; (1) insufficient food access by household, 2) inadequate maternal and child health care, 3). insufficient health services and environmental sanitation. Whiles these factors are on its own insufficient to explain variations in dietary diversity status of rural households across the world; it offers an integrated pathway for global eradication of malnutrition through political economy revised approaches. Other findings have called for incorporation of the 'health crisis' model put forth by de Waal (1989) as a principal component for assessement nutritional security.

\section{Coping Strategies of Rural Households}

Sustainable and resilient dietary diversity outcomes are underpinned by both food adequacy and successful adaptations of resource-poor to risks factors imposed by climate change and environmentally degradable high-risk agricultural production systems. The common strategies used by resource-poor to circumvent the negative effects of food energy stress include; 1) Genetic adaptations 2) Physiological coping strategies 3). Behavioral adaptive mechanisms (Ike, Jacobs, \& Kelly, 2017; Heady \& Eckerd, 2012; Payne \& Lipton, 1990; Waterlow, 1988).

\subsection{Genetic Adaptive Capacity to Food Stress}

The genetic composition of rural households to some extent determines their adaptive responses and survival to nutritional deficiencies (Chamberlina \& Jayne, 2020; Ditcher, Ballard, Swindale \& Coates, 2011). The capacity for 
genetic adaptation influences social choices and responses to poor household dietary diversity and malnutrition.

\subsection{Physiological Inclinations to Food Stress}

The physiological make - up of resource-poor determines the coping strategies they adapt to food stress (Biederlack \& Rivers, 2009). There are acute variations in the capacity of individuals to withstand the energy stresses imposed by lack of nutrients in diets. Depending on the body mass and size of members of the rural household food stress could be minimal (Na \& Mehra, 2016). The physiological adjustments to food stress as in reduced- body masses and weight losses reflect the changes in energy levels of household members.

A change in metabolic rates due to food stress results in a massive decline of fertility rate of young women and stunted growth in pre-schoolers. The early growth of children is significant in human capital development as their capacity to withstand physiological stress or excel in educational pursuits depends on this type of adjustment. It is reported by studies in rural Africa that children who accumulated saved energy in excellent childhood breastfeeding and nourishment programmes are the most physiologically adapted to energy stress as adults (Abebaw et al., 2020; Coates, 2015).The prevalence of minimal growth retardation rate in rural children would determine the overall survival rate of the rural household. High rates of growth retardation in children would be unacceptable under stressful physiological adaptation and could cause mental impairment later in adult life (Beaton, 1989).

Studies have also shown that growth failures and under-nutrition in pre-schoolers increases the risk of mortality (Abebaw et al., 2020; Katz, 1989; Heywood, 1982; Chen, 1980). Severe malnutrition increases the incidence, duration and severity of infectious diseases as well (Tomkins \& Watson, 1989). It is the goal of this study to prompt responses which increase the risk of human capital decline in environments prone to natural hazards of transmission of communicable diseases in the Northern parts of rural Africa such as Ghana, Nigeria, Mali, Bukina Faso, Senegal and Guinea.

\subsection{Behavioural}

Behavioural adaptations reflect the set of activities that resource-poor undertake to reduce energy expenditure in an attempt to reduce the devastating impact of the nutritional deficiency on well-being (Coates, Swindale, \& Bilinsky, 2007b). Adults engage in behavioural activities which encourage energy preservation such as less involvement in intensive farm labour activities and livestock rearing. In most parts of Africa, the children reduce play and work to conserve energy reserves. However, poor rural households would be unable to reduce energy expenditure and may expend more energy seeking food in periods of energy stress. The most affected would be the resource-poor who have saved less energy over the previous seasons or have no livestock assets to smoothen consumption.

During periods of food energy stress survival is paramount. Rural households are faced with several choices to reduce distress. The coping strategies they adapt in response to these choices depend on their perceptions of the costs and risk involved. The choices they make relate to current and future dietary diversity needs and what they are willing to sacrifice. In most parts of Africa, children may go hungry in droughts or denied access to education so they may earn income or preserve energy. As a customary practice, the acceptance of a minimal level of hunger and malnutrition is a strategy to ensure future food security in seasons of food deprivation (Abebaw et al., 2020; Corbette, 1988). This is not to be mis-interpreted as backwardness or lack of care of children or ignorance of the nutritional needs of children.

This implies that in the analysis of dietary deficiency of resource-poor households, growth failure of pre-schoolers under five may not be the most important indicator of malnutrition rather food intake as an outcome of nutritional security is important in measuring rural households processes toward future food security. An estimation of rural household food insecurity by food intake models are more closely related indicators of food and nutritional insecurity rather than its evaluation through growth failure models (Malang \& Holzinger, 2020; Gillespie \& Mason, 1991). This raises important questions for improving food in-take models for efficient and sustainable analysis of household dietary diversity especially in the northern parts of Ghana and Nigeria. The major gap in household dietary diversity analysis is the inability of studies to clearly establish the boundaries and minimum energy thresholds below which a rural household is considered food and nutritionally insecure.

\section{Livelihood Strategies of Households in Response to Nutritional Deficiency}

Modern food security and dietary diversity studies support an environment and income diversification approach to hunger and famine eradication in rural Africa (Gershon, Ansah, Marfo \& Donkoh, 2020). It is often argued in the development literature that rural households achieve food security and nutritional diversity at the expense of the environmental degradation and less income diversification of agricultural activities. However, studies point out that rural households do not make distinctions between food security and income diversification activities. They seek to 
maximize the best options and outcomes from their game with nature and the environment. They have vested interest in maximising income returns from diversification opportunities as well as enhancing food and nutritional outcomes (Marafa, May \& Tenebe 2020).

This view concurs with Maxwell (1991), who argued that food security would only be attained when resource poor become efficient and resilient at income diversification activities. In practical terms, rural households would decrease consumption to protect livelihoods and increase income savings as wealth accumulation strategy (Ickowitz, Powell, Roland, Jones, \& Sutherland, 2019). This has several implications for food and nutritional diversity studies. First, to the resource-poor food may not come first as often as implied in the development literature. Second, food cannot be seen as a unique object to be sought by resource poor to the exclusion of all other priorities such as wealth accumulation (Johny, Wichmann, \& Swallow, 2017).

Thirdly, within the same rural poor communities it is important to establish food security norms on a participative basis rather than impose it on all rural households. For many rural households the security sought could be more income-based than any other concern especially for modern capitalist economies linking rural communities to urban centres. Fourthly, information systems for rural household poverty analysis should not only be concerned with 'food flows' but also income flows. Finally, addressing food and nutrition security of rural households opens a new dimension which promotes rural income diversification as a resilience building mechanism against food stress in rural Africa (Salifu, 2020).

\section{Classification of Households' Resilience to Nutritional Insecurity}

The economic welfare literature discusses resilience to food insecurity and low dietary diversity in the notion of the resource-poor's responses to climate change risks threatening the state of imperturbability of food consumption patterns in the developing world (Salifu, 2019; Li, Deng, \& Zhou 2019; Scoones, 1998; Chambers, 1988).

It is argued that to achieve global food security goals, better-off households that are classified as food secure households should not only be capable of meeting the dietary consumption needs in the short-term but capable of developing the resilient and sustainable internal mechanisms to face crises threatening food consumption (Chamberlina \& Jayne, 2020; Oshaug, 1985). Adaptations of households to sustainable food consumption patterns have been classified depending on their capacity to endure food stresses without a decline in progress to food security and stability (Loison, 2019). These classifications are drawn along the lines of household resilience to natural shocks, diseases and food insecurity. These are 1) 'Highly-resilient' households, 2) Moderately 'resilient' households 3), Less-resilient households.

\subsection{Highly-Resilient Rural Households}

Highly resilient households are characteristically capable of withstanding food stress from season to season on a continuous basis without running the risk of breaking the flow of household consumption patterns due to low incomes. These households are the most enduring class of households resistant to food insecurity and energy stress (Lovo \& Veronesi, 2019).

\subsection{Resilient Rural Households}

Moderately Resilient Households though inclined to suffer some natural shocks, are well capable of rebounding from these food shocks and environmental stresses occasioned by declining real incomes through market failure in production agriculture. This category of households constitutes the transient-food insecure class of rural poor in the developing world. They are highly adaptable to the changing conditions and hazards of their environment (Malang \& Holzinger, 2020).

\subsection{Less-Resilient Rural Households}

Less-resilient households are not capable of withstanding food stress for longer periods of time. They are acutely food insecure and extremely slow to recovery from shocks and if they ever do recover at one moment they remain increasingly food insecure in ensuing seasons. These are the chronically food insecure households of rural populations which need targeted cash tranfers for survival (McMillan, Rodrik, \& Sepulveda, 2017).

\section{Conclusions and Recommendations for Further Research}

This paper provides a summary of the theoretical concepts of household dietary diversity and response of resource-poor households around the world to varied forms of global hunger and malnutrition based on an extensive review of 100 works compiled from all continents of the world. Several findings have been identified by this review which raises important questions, issues and gaps for further research. Firstly, the goal of attainment of sustainable household dietary diversity is not only an issue of global concern captured by the sustainable development goals but 
highlights the impact of natural and economic shocks on household welfare. Secondly, it emphasizes the need for global household dietary diversity research to capture malnutrition related aspects of rural household's lived experiences. Thirdly, it raises the new argument that the analysis of sustainable rural household dietary diversity can no longer be divorced from the political economy constraints and capabilities to economic well-being. The paper identifies political economy analysis of household dietary diversity as a fundamental tool for effective, sustainable and resilient poverty reduction in the developing world. This paper contributes to the international development literature by providing a synthesis of research works undertaken over the last 70 years and indicating gaps in the literature which may prompt new research works to advance household dietary diversity studies in global dietary dieversity administration as an important policy tool to reduce under-development around the world.

\section{References}

Abebaw, D., Admassie, A., Kassa, H., \& Padoch, C. (2020). Can rural outmigration improve household food security?. Empirical evidence from Ethiopia. World Development, 129, 104879. https://doi.org/10.1016/j.worlddev.2020.104879

ACCN/SCN. (1991). Some options for improving Nutrition in the 90s. SCN, News No.7, ACC/SCN, Geneva.

Adelekan, A., \& Omotayo, A. O. (2017). Linkage between rural non-farm income and agricultural productivity in Nigeria: A Tobit-Two-Stage Least Square regression approach. $J$ Dev Areas, 51(3), 317-333. https://doi.org/10.1353/jda.2017.0075

Adjei, P. O. W., Adjei, J. O., \& Serbeh, R. (2020). Looking beyond cash transfers for optimizing poverty reduction and livelihood sustainability in rural Ghana: comparative analysis of two socialpolicy interventions against poverty. Poverty and Public Policy, 12(1), 84-111. https://doi.org/10.1002/pop4.270

Ahmed, A., \& Gasparatos, A. (2020). Multi-dimensional energy poverty patterns around industrial crop projects in Ghana: Enhancing the energy poverty alleviation potential of rural development strategies. Energy Policy, 137, 111123. https://doi.org/10.1016/j.enpol.2019.111123

Akinrinde, A. F., Omotesho, K. F., \& Ogunla, I. (2018). The issue of income diversification among rural farming households: Empirical evidence from Kwara state, Nigeria. Journal of Agribusiness and Rural Development, 3(49), 231-238. https://doi.org/10.17306/J.JARD.2018.00427

Alcona, F., Marín-Miñanoa, C., Zabalaa, J. A., Doloresde-Miguela, M., \& Martínez-Paz, J. M. (2020). Valuing diversification benefits through intercropping in Mediterranean agroecosystems: A choice experiment approach. Ecological Economics, 171, 106593. https://doi.org/10.1016/j.ecolecon.2020.106593

Allanson, P., Kasprzyk, K., \& Barnes, A. P. (2017). Income Mobility and Income Inequality in Scottish Agriculture. Journal of Agricultural Economics, 68(2), 471-493. https://doi.org/10.1111/1477-9552.12192

Amadou, Z. (2019). Food and income diversification decisions as climate change adaptation strategies: Evidence from Kalfou and Tabalak local governments, Tahoua State, Niger Republic. Journal of Development and Agricultural Economics, 11(7), 152-161. https://doi.org/10.5897/JDAE2018.0997

Anaman, K. A. (2018). Economic shocks and growth in the post-independence period, 1957 to 2017. Accra: Institute of Fiscal Studies.

Angelsen, A., Jagger, P., Babigumira, R., Belcher, B., Hogarth, N. J., Bauch, S., ... Wunder, S. (2014). Environmental income and rural livelihoods: A global comparative analysis. World Development, 64, S12-S28. https://doi.org/10.1016/j.worlddev.2014.03.006

Ashley, C., \& Carney, D. (1999). Sustainable livelihoods: Lessons from early experience. London: Department for International Development (DFID).

Attanasio, O. P., \& Sze' Kely, M. (2004). Wage shocks and consumption variability in Mexico during the 1990s. Journal of Development Economics, 73(1), 1-25. https://doi.org/10.1016/j.jdeveco.2003.01.001

Ayele, B. (2019). Revisiting the status of pastoral women's access to and control over livelihood assets; evidences from Fafan zone, Somali region, Ethiopia. Journal of Agricultural Extension and Rural Development, 11(6), 114-127. https://doi.org/10.5897/JAERD2019.1058

Balana, B. B., Bizimana, J., Richardson, J. W., Lefore, N., Adimassa, Z., \& Herbst, B. K. (2020). Economic and food security effects of small-scale irrigation technologies in northern Ghana. Water Resources and Economics, 29, 100141. https://doi.org/10.1016/j.wre.2019.03.001 
Baliki, G., Brück, T., \& Stojetz, W. (2018). Drivers of resilience and food security in North-east Nigeria: Learning from micro data in an emergency setting. ISDC, Berlin.

Baraclough, S. L., \& Scott, M. F. (1988). The Rich Have Already Eaten. Roots of Catrosphe in Central America, working paper 105, Hellen Kellog Institute for International Studies, University of Notre Daime, USA.

Barrett, C. B., Bezuneh, M., \& Aboud, A. (2001). Income diversification, poverty traps and policy shocks in Côte d'Ivoire and Kenya. Food Policy, 26(4), 367-384. https://doi.org/10.1016/S0306-9192(01)00017-3

Bebbington, A. (1999). Capitals and capabilities: a framework for analysing peasant viability, rural livelihoods and poverty. World Development, 27(12), 2021-2044. https://doi.org/10.1016/S0305-750X(99)00104-7

Bellemare, M. F. (2015). Rising food prices, food price volatility, and social unrest. American Journal of Agricultural Economics, 97(1), 1-21. https://doi.org/10.1093/ajae/aau038

Bellon, M. R., Kotu, B. H., Azzarri, C., \& Caracciolo, F. (2020). To diversify or not to diversify, that is the question. Pursuing agricultural development for smallholder farmers in marginal areas of Ghana. World Development, 12, 104682. https://doi.org/10.1016/j.worlddev.2019.104682

Béné, C. (2020). Resilience of local food systems and links to food security - a review of some importantconcepts in the context of COVID-19 and other shocks. Food Security. https://doi.org/10.1007/s12571-020-01076-1

Bickel, G. W., Andrews, M. S., \& Klein, B. W. (1996). Measuring food security in the United States: a supplement to the CPS. In D. Hall, \& M. Stavrianos (Eds.), Nutrition and food security in the food stamp program USD a food and consumer service Alexandria, VA.

Bickel, G., Nord, M., Price, C., Hamilton, W., \& Cook, J. T. (2000). Measuring Food Security in the United States: Guide to Measuring Household Food Security, rev. 2000 USDA/FNS/OAE Alexandria, VA.

Brück, T., \& D'Errico, M. (2019). Food security and violent conflict: Introduction to the special issue. World Development, 117, 167-171. https://doi.org/10.1016/j.worlddev.2019.01.007

Cai, J., Ma, E., Lin, J., et al.. (2020). Exploring global food security pattern from the perspective of spatio-temporal evolution. J. Geogr. Sci., 30, 179-196. https://doi.org/10.1007/s11442-020-1722-y

Cameron, L. A., \& Worswick, C. (2003). The labor market as a smoothing device: labor supply responses to crop loss. Review of Development Economics, 7(2), 327-341. https://doi.org/10.1111/1467-9361.00194

Campbell, D. J. (1990). Community-based Strategies for coping with Food Scarcity: a role in Africa. Famine Early Warning System, 20(3), 231-241. https://doi.org/10.1007/BF00642988

Castro-Arce, K., \& Vanclay, F. (2020). Transformative social innovation for sustainable rural development: An analytical framework to assist community-based initiatives. Journal of Rural Studies, 74, 45-54. https://doi.org/10.1016/j.jrurstud.2019.11.010

Chamberlina, J., \& Jayne, T. S. (2020). Does farm structure affect rural household incomes? Evidencefrom Tanzania. Food Policy, 90, 101805. https://doi.org/10.1016/j.foodpol.2019.101805

Chambers, R., \& Conway, G. (1992). Sustainable rural livelihoods: practical concepts for the 21st century. IDS Discussion Paper 296, Institute of Development Studies, Brighton, Sussex, UK.

Chen, L., et al.. (1980). Anthropometric assessment of energy-protein malnutrition and the rise of mortality among pre-school aged children. Nutrition, 38, 1836-1845. https://doi.org/10.1093/ajcn/33.8.1836

Coates, J. (2015). Food insecurity measurement. Food Ins. Pub. Health, 51-64. https://doi.org/10.1201/b18451-4

Coates, J., Swindale, A., \& Bilinsky, P. (2007b). Household Food Insecurity Access Scale (Hfias) for Measurement of Food Access: Indicator Guide. Washington, DC: Food and Nutrition Technical Assistance Project. Academy for Educational Development, 34. https://doi.org/10.1037/e576842013-001

Colebatch, H. K. (2017, May). The idea of policy design: intention, process, outcome, meaning and validity. Public Policy and Administration, 18, 365-383. https://doi.org/10.1177/0952076717709525

D'Errico, M., Romano, D., \& Pietrelli, R. (2018). Household resilience to food insecurity: evidence from Tanzania and Uganda. Food Security, 10(4), 1033-1054. https://doi.org/10.1007/s12571-018-0820-5

Dapilah, F., Nielsen, J. O., \& Friis, C. (2020). The role of social networks in building adaptive capacity and resilience to climate change: a case study from northern Ghana. Journal of Climate and Development, 12(1), 42-56. https://doi.org/10.1080/17565529.2019.1596063 
Davis, B., Di Guiseppe, S., \& Zezza, A. (2017). Are Africans (not) leaving agriculture? Patterns of household income sources in rural Sub-Saharan Africa. Food Policy, 67, 153-174. https://doi.org/10.1016/j.foodpol.2016.09.018

De Janvry, A., \& Sadoulet, E. (2006). Progress in the modeling of rural households' behavior under market failures. In A. De Janvry, \& R. Kanbur (Eds.), Poverty, inequality and development (pp. 155-181). New York, NY: Springer. https://doi.org/10.1007/0-387-29748-0_9

Deaton, B. J., \& Lipka, B. (2015). Political instability and food security. Journal of Food Security, 3(1), 29-33. https://doi.org/10.12691/jfs-3-1-5

Dedehouanou, S. F. A., \& McPeak, J. (2019). Diversify more or less? Household income generation strategies and food security in rural Nigeria. The Journal of Development Studies. https://doi.org/10.1080/00220388.2019.1585814

Dedehouanou, S. F. A., Araar, A., Ousseini, A., Abdoulaziz, L. H., \& Jabir, M. (2018). Spillovers from off-farm self-employment opportunities in rural Niger. The Journal of Development Studies. https://doi.org/10.1016/j.worlddev.2017.12.005

Devereux, S., Béné, C., \& Hoddinott, J. (2020). Conceptualising COVID-19's impacts on household food security. Food Sec., 12, 769-772. https://doi.org/10.1007/s12571-020-01085-0

Ding, Z., \& Abdulai, A. (2020). An analysis of the factors influencing choice of microcredit sources and impact of participation on household income. Journal of International Development. https://doi.org/10.1002/jid.3466

Dithmer, J., \& Abdulai, A. (2017). Does trade openness contribute to food security? A dynamic panel analysis. Food Policy, (69), 218-230. https://doi.org/10.1016/j.foodpol.2017.04.008

Durão, S., Visser, M., Kredo, T., et al.. (2020). Assessing the completeness and comparability of outcomes in systematic reviews addressing food security: protocol for a methodological study. Syst Rev, 9, 9. https://doi.org/10.1186/s13643-019-1268-1

Dzanku, F. M. (2019). Food security in rural sub-Saharan Africa: Exploring the nexus between gender, geography and off-farm employment. World Development, 113, 26-43.

Dzanku, F. M., \& Sarpong, D. (2011). Agricultural diversification, food self-sufficiency and food security in Ghana CABI. Wallingford, UK Google Scholar. https://doi.org/10.1016/j.worlddev.2018.08.017

Ecker, O. (2018). Agricultural transformation and food and nutrition security in Ghana: Does farm production diversity (still) matter for household dietary diversity?. Food Policy, 79, 271-282. https://doi.org/10.1016/j.foodpol.2018.08.002

Eide, A. (1986). Rights to adequate food as a human right. Centre for Human Rights, Geneva.

FAO, IFAD, UNICEF, WFP, \& WHO. (2018). The State of Food Security and Nutrition in the World 2018: Building climate resilience for food security and nutrition. FAO, Rome.

FAO, IFAD, UNICEF, WFP, \& WHO. (2019). The State of Food Security and Nutrition in the World 2018: Safeguarding against economic slowdowns and downturns. FAO, Rome.

Faulkner, J., Murphy, E., \& Scott, M. (2019). Rural household vulnerability; a decade after the great financial crisis. Journal of Rural Studies, 72(1), 240-251. https://doi.org/10.1016/j.jrurstud.2019.10.030

Fentahun, G. E., Seid, S., \& Biruk, K. (2018). The role of income diversification on risk management and rural household food security in Ethiopia. Journal of Economics and Sustainable Development, 9, 9.

Fentahun, G. E., Seid, S., \& Biruk, K. (2018). The role of income diversification on risk management and rural household food security in Ethiopia. Journal of Economics and Sustainable Development, 9, 9.

Forero-Cantor, G., Ribal, J., \& Sanjuán, N. (2020). Measuring regional differences in food security from access and stability dimensions: A methodological proposal based on elasticities. Agric. Econ., 66, 112-119. https://doi.org/10.17221/97/2019-AGRICECON

Gershon, I., Ansah, K., Marfo, E., \& Donkoh, S. A. (2020). Food demand characteristics in Ghana: An application of the quadratic almost ideal demand systems. Scientific African, 8, e00293. https://doi.org/10.1016/j.sciaf.2020.e00293 
Gillespie, S., \& Mason, J. (1991). Nutrition-Relevant Actions; some Experinecs from the Eighties and Lessons for the Nineties. Nutrition Policy Discussions paper, no. 10, ACC/SCN, Geneva.

Headey, D. (2013). Developmental drivers of nutritional change: A cross-country analysis. World Development, 42(2), 76-88. https://doi.org/10.1016/j.worlddev.2012.07.002

Heltberg, R., \& Lund, N. (2009). Shocks, coping, and outcomes for Pakistan's poor: health risks predominate. Journal of Development Studies, 45(6), 889-910. https://doi.org/10.1080/00220380902802214

Hopkins, R. F. (1986). Food security, Policy Options and Evolution of State responsibility. In F. L. Tullis, \& W. L. Hollist, (Eds.), Food, the state and international political economy: dilemmas of developing countries. University of Nebraska press, Lincoln and London.

Johny, J., Wichmann, B., \& Swallow, B. M. (2017). Characterizing social networks and their effects on income diversification in rural Kerala, India. World Development, 94, 375-392. https://doi.org/10.1016/j.worlddev.2017.02.002

Kahsay, S., \& Mulugeta, M. (2014). Determinants of rural household food insecurity in Laelay Maichew Woreda Tigray, Ethiopia. Africa Journal Agric Food Security, 2(1), 105-111.

Kirk, A., Kilic, T., \& Carletto, C. (2018). Composition of Household Income and Child Nutrition Outcomes Evidence from Uganda. World Development, 109, 452-469. https://doi.org/10.1016/j.worlddev.2017.03.023

Laborde, D., Martin, W., \& Vos, R. (2020). Poverty and food insecurity could grow dramatically as COVID-19 spreads. Blog published by the International Food Policy Research Institute (IFPRI). https://doi.org/10.2499/p15738coll2.133762_02

Lang, T., \& Barling, D. (2012). Food security and food sustainability: Reformulating the debate. The Geographical Journal, 178(4), 313-326. https://doi.org/10.1111/j.1475-4959.2012.00480.x

Lax, J., \& Köthke, M. (2017). Livelihood strategies and forest product utilisation of rural households in Nepal. Small-Scale Forestry, 16(2), 1-16. https://doi.org/10.1007/s11842-017-9367-0

Malang, T., \& Holzinger, K. (2020). The political economy of differentiated integration: The case of common agricultural policy. The Review of International Organizations. https://doi.org/10.1007/s11558-020-09384-z

Marafa, L., May, J., \& Tenebe, V. A. (2020). Upscaling Agriculture and Food Security in Africa in Pursuit of the SDGs: What Role Does China Play?. In M. Ramutsindela, \& D. Mickler (Eds.), Africa and the sustainable development goals, Sustainable Development Goals Series. Springer, Cham. https://doi.org/10.1007/978-3-030-14857-7_16

Masset, E., García-Hombrados, J., \& Acharya, A. (2020). Aiming high and falling low: The SADA-Northern Ghana Millennium Village Project. Journal of Development Economics, 143, 102427. https://doi.org/10.1016/j.jdeveco.2019.102427

Maxwell, S. (1990). Food security in developing countries; issues and options for the 1990s. IDS Bulletin, 22(3), 2-13. https://doi.org/10.1111/j.1759-5436.1990.mp21003002.x

Mellor, J. (1988). Global Food Balance and Food Security. World Development, 16(9), 997-1011. https://doi.org/10.1016/0305-750X(88)90104-0

Meraner, M., Pölling, B., \& Fingera, R. (2018). Data on farm diversification decisions and farmers' risk preferences in the Ruhr Metropolitan region (Germany). Data in Brief, 18, 9-12. https://doi.org/10.1016/j.dib.2018.03.008

Messer, E. (1990). Food wars: hunger as a weapon of war in the hunger report: the Alan Shawn feinstein world hunger problem. Brown University, Providence.

Mubaya, C. P., \& Mafongoya, P. (2016). Local-level climate change adaptation decision-making and livelihoods in semi-arid areas in Zimbabwe. Environment Development \& Sustainability, 19(6), 1-27. https://doi.org/10.1007/s10668-016-9861-0

Mulwa, C. K., \& Visser, M. (2020). Farm diversification as an adaptation strategy to climatic shocks and implications for food security in northern Namibia. World Development, 129, 104906. https://doi.org/10.1016/j.worlddev.2020.104906

Nakajima, M., Otsuka, K., \& Yamano, T. (2018). Jobs off the farm: wealth, human capital, and social group in rural eastern India. Journal of Development Studies, 54(1), 111-132. https://doi.org/10.1080/00220388.2017.1283017 
Narayanan, S. (2020). Food and agriculture during a pandemic: Managing the consequences. Blog published by Ideas for India.

Oshaug, A. (1985). The Composite Concept of Food security. In W. B. Eide (Ed.), Introducing nutritional considerations into rural development programmes with focus on Agric.: A theoretical contribution. Development of Methodology for Evolution of Nutritional Impact research, University of Oslo, June.

Payne, P. (1990). Measuring Malnutrition. IDS Bulletin, 21(3), 14-30. https://doi.org/10.1111/j.1759-5436.1990.mp21003003.x

Pritchard, R., Grundy, I. M., Horst, D., \& Ryan, C. M. (2019). Environmental incomes sustained as provisioning ecosystem service availability declines along a woodland resource gradient in Zimbabwe. World Development, 122, 325-338. https://doi.org/10.1016/j.worlddev.2019.05.008

Raphael, D. D. (1967). Political theory and rights of man. Macmillan London.

Ravallion, M., \& Chaudhuri, S. (1997). Risk and insurance in village India: comment. Econometrica, 65(1), 171-184. https://doi.org/10.2307/2171818

Reardon, T. (1997). Using evidence of household income diversification to inform study of the rural nonfarm labor market in Africa. World Development, 25(5), 735-747. https://doi.org/10.1016/S0305-750X(96)00137-4

Salifu, G. A. N. (2019b). The Political Economy Dynamics of Rural Household Income Diversification: Review of the international literature. Research in World Economy, 10(3), 10-34. https://doi.org/10.5430/rwe.v10n3p273

Salifu, G. A. N. (2020). Political economy analysis of income diversification activities of rural households and food security: a case study of yendi and nanumba north districts of the Northern Region of Ghana. Unpublished Doctoral Thesis, Department of Agricultural Economics and Agribusiness, University of Ghana. https://doi.org/10.11114/aef.v6i5.4405

Salifu, G. A. N., \& Anaman, K. A. (2019a). Political economy analysis of Income diversification of Rural Households in the Northern Region of Ghana. Applied Economics and Finance, 6(5), 10-34. https://doi.org/10.11114/aef.v6i5.4405

Seidu, A. A., Ahinkorah, B. O., \& Agbablo, E. (2020). Food Insecurity among In-school Adolescents in Ghana: What are the Determinants? Journal of Hunger \& Environmental Nutrition. https://doi.org/10.1080/19320248.2020.1745723

Tithy, D., Naznin, S., \& Elias, H. (2017). Analysis of the impact of income diversification strategies on food security status of rural households in Bangladesh: A case study of rajshahi district. American Journal of Theoretical and Applied Business, 2(4), 46-56.

Upton, J. B., Cissé, J. D., \& Barrett, C. B. (2016). Food security as resilience: Reconciling definition and measurement. Agricultural Economics, 47(S1), 135-147. https://doi.org/10.1111/agec.12305

World Bank. (2020). Brief: Food security and Covid-19.

Wuepper, D., Sauer, J., \& Kleemann, L. (2018). Social capital, income diversification and climate change adaptation: panel data evidence from Rural Ethiopia. Journal of Agricultural Economics, 69(2), 458-475. https://doi.org/10.1111/1477-9552.12237

Yobe, C. L., Mudhara, M., \& Mafongoya, P. (2019). Livelihood strategies and their determinants among smallholder farming households in KwaZulu-Natal province, South Africa. Agrekon, 58(3), 340-353. https://doi.org/10.1080/03031853.2019.1608275

\section{Copyrights}

Copyright for this article is retained by the author(s), with first publication rights granted to the journal.

This is an open-access article distributed under the terms and conditions of the Creative Commons Attribution license (http://creativecommons.org/licenses/by/4.0/). 